\title{
Online Neurological Registries
}

\author{
Megan Johnston ${ }^{1,8}$, Craig Campbell ${ }^{2}$, Glenys Godlovitch ${ }^{3}$, Lundy Day ${ }^{1,8}$, \\ Julie Wysocki ${ }^{4}$, Lynn Dagenais ${ }^{5}$, Nathalie Jette ${ }^{7,8}$, Lawrence Korngut ${ }^{1,8}$, \\ Tamara Pringsheim ${ }^{1,8}$, Ruth Ann Marrie 6
}

Can J Neurol Sci. 2013; 40: Suppl. 2 - S41-S45

This section of the guideline focuses on the specific issues and special considerations that surround online registries. In developing this section of the guideline we reviewed available literature; consulted with disease, registry, ethics, privacy, legal and information technology (IT) experts, and derived expert consensus recommendations.

\section{BACKGROUND}

What is an online registry?

The term "online registry" is poorly defined in the literature. This may refer to a method of data collection or data dissemination, and may capture data directly from providers, patients or both. Data may be entered retrospectively or prospectively, as with other registries. Existing registries range from those where data are entered directly through an online interface into a local or central data repository, and where data are not accessible to local sites to those where aggregate data are available to all sites and to those that facilitate patient networking. A summary of possible features and some case examples of registries that employ these features are below in Table 9 .

\section{The Global Landscape}

Worldwide, evidence is growing that disease registries can enhance the understanding of rare diseases. In 2010, the National Institutes of Health (NIH) in the United States organized a workshop "Advancing Rare Disease Research: The Intersection of Patient Registries, Biospecimen Repositories, and Clinical Data" held in Bethesda Maryland. Over two days,

Table 9: Possible Registry Features and Case Examples

\section{REGISTRY FEATURES}

Simple database software collects electronic data centrally or at local sites. Paper forms might help to mediate the electronic data collection. There is no electronic access to data by sites and no sharing of data in real time.

Complex database software collects electronic data from registry participants and other sources such as electronic health records. Data is collected at local sites and entered over the World Wide Web. Paper forms may be used to mediate data collection. Sites do have access to local data and reporting is available in real time.

Complex database software collects electronic data from registry participants and other sources such as electronic health records. Data is collected at local sites and entered over the World Wide Web. Paper forms may be used to mediate data collection. Sites do have access to local data and reporting is available in real time. Additionally, aggregate data can be made available to participating centres or the broader research community.

Complex database software collects electronic data from registry participants and other sources such as electronic health records. Data is collected at local sites and entered over the World Wide Web. Paper forms may be used to mediate data collection. Sites do have access to local data and reporting is available in real time. Additionally, aggregate data can be made available to participating centres or the broader research community. This type also adds practitioner research networking through support mechanisms such as a portal, email, and other tools.

Complex database software collects electronic data from registry participants and other sources such as electronic health records. Data is collected at local sites and entered over the World Wide Web. Paper forms may be used to mediate data collection. Sites do have access to local data and reporting is available in real time. Additionally, aggregate data can be made available to participating centres or the broader research community. This type also adds practitioner research networking through support mechanisms such as a portal, email, and other tools. Finally this type also includes patient networking and direct access through forums, portal tools, newsletters etc.

\section{EXAMPLE}

Simple clinic database at a single site (e.g. an Access database in a neuromuscular clinic). US ALS Registry ${ }^{(160)}$

http://wwwn.cdc.gov/ALS/AboutRegistry.aspx

Duchenne Connect ${ }^{(161)}$

https://www.duchenneconnect.org/

\section{MS Base $^{(162)} ;$ EULAR $^{(163)}$}

https://www.msbase.org/msbase/en/msbase/pu b/home;jsessionid=dlygajmrqijx 188 ceum $70 \mathrm{~m}$ 3h0 http://www.eular.org/

Patients Like Me ${ }^{(164)}$

http://www.patientslikeme.com/

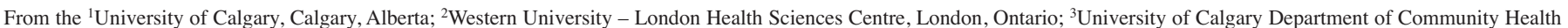

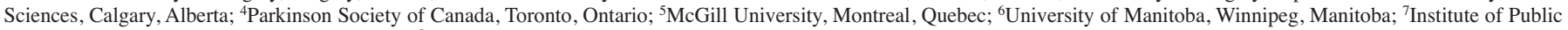
Health, University of Calgary, Calgary, Alberta; ${ }^{8}$ Hotchkiss Brain Institute, University of Calgary, Calgary, Alberta, Canada.

FinAl Revisions SubmitTed JANUARY 28, 2013.

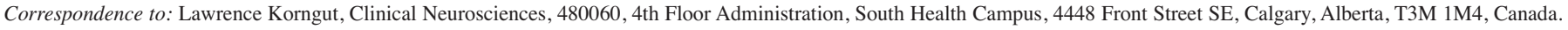
Email: Lawrence.korngut@albertahealthservices.ca. 
several hundred attendees discussed the creation of a global internet-based rare disease registry. ${ }^{165}$ In 2011, the EPIRARE (European Platform for Rare Disease Registries) project conducted a survey to examine the currently functioning rare disease registries across Europe and other countries and explore problems, needs, resources and expectations with the goal of developing tools to support existing registries and to facilitate the development of new registries where needed. ${ }^{166}$ As of July 16, 2012 over $80 \%$ [62\% (2000-2011) and 20\% (1990-1999)] of the registry custodians responding to the survey indicated they had collected their first case within the last 20 years. Ninety percent of registries responding were actively collecting data ${ }^{166}$. Of particular note was the fact that approximately $75 \%$ of the registries responding to the survey had fewer than 2000 patients enrolled. ${ }^{166}$ This clearly demonstrates a factual basis for assertions made at the NIH workshop indicating that a key barrier to implementing a global rare disease registry platform was a lack of compatibility across existing registries and especially a lack of ability to use existing pockets of data. ${ }^{165}$

Another notable result was that over $50 \%$ of the registries indicated that they were either using their own diagnostic coding system or no coding system at all. ${ }^{166}$ This is likely a direct result of the lack of rare disease codes in the World Health Organization's International Classification of Diseases 10th edition (ICD-10) featuring codes for only 500 of the perhaps 6000 rare diseases currently described worldwide. ${ }^{167}$

Over $80 \%$ of registries completing the EPIRARE survey indicated they obtained some of their information from clinics and only $8 \%$ indicated that data was collected online from patients. ${ }^{166}$

Finally, approximately $70 \%$ of registries completing the EPIRARE survey indicated that it would be helpful for the EPIRARE initiative to provide IT tools including for example database software or secured data exchange. ${ }^{166}$ Attendees at the NIH workshop identified a clear gap associated with the IT infrastructure required to facilitate a global rare disease registry. Specifically, while the technology exists and can be relatively easily implemented a more pressing question was addressing the multi-faceted definitions associated with the possible data fields across potentially millions of enrollees and thousands of diseases. ${ }^{165}$ While it was clear that an online platform would provide efficiencies of scale and cost with respect to data collection and recruitment, the exact method by which the software would be designed and constructed would be the subject of substantial follow-up discussion. ${ }^{165}$ It is clear that considerable discussion around the ideal online registry scenario remains. This guideline therefore outlines the basic elements that can be implemented and the considerations that should be made in carrying out your own registry discussions.

\section{Relevant Literature}

Online databases and websites can be used to increase recruitment of participants into investigator-driven drug trials. Bergin et al successfully implemented an internet database that allowed physicians to register patients for epilepsy trial recruitment online from routine clinics. ${ }^{62}$ The database was also effective at randomizing patients for controlled trials. This method proved to be useful with three quarters of neurologists indicating a willingness to participate. Information was collected easily and efficiently and allowed participants to be recruited from multiple locations from eight cities in New Zealand.

The feasibility of web-based online registries was examined by Wild et al. who developed a free, international, internet registry of femoral nail complications. ${ }^{168}$ Participation was voluntary and access was open to anyone. Agreement to consecutively enter all cases was required. Participants from 25 countries submitted anonymized patient data through online questionnaires. Originally results produced $13.4 \%$ incomplete and $19.3 \%$ inconsistent data. However, after revision of questionnaires to include a minimal data set, only drop boxes and check boxes and the inclusion of automated plausibility checks to rule out wrong data, incomplete and inconsistent data decreased to $2.9 \%$ and $0 \%$ respectively. Automatic, real-time evaluation of the data was also implemented displaying graphical results. This method provides fast, easy access to international registry data.

The internet may also be used to recruit registry participants via social networking websites. Tweet et al examined the feasibility of developing a virtual multi-centre registry of individuals with spontaneous coronary artery dissection using an online disease specific social media support network. ${ }^{169}$ A pilot study of 12 participants proved this method to be fast and feasible for recruitment, case ascertainment, retrospective and prospective data collection. Researchers were able to identify and notify potential participants through the social media networking site, send and collect consent forms and questionnaires and collect and analyze medical records and imaging data. This innovative method could be potentially useful to create multi-centre, online rare disease registries at a low-cost.

Web-based systems of data collection have been developed in order to reduce manual data entry, improve quality, recruit patients and link patient data. Hess et al 2005 created a data collection system that used touch-screen computers to collect self-reported patient data in a pilot study of 86 consecutive patients aged 19 to 84 seen at a general medicine practice. ${ }^{27}$ This system proved to be time efficient and user-friendly. Results showed that all patients completed the questionnaire (majority within 15 minutes), 81 individuals reported no difficulty using the tool, five patients reported some difficulty and no patients reported considerable difficulty. Additionally patients were asked if they would like to join a research registry project and be placed on a prospective subject list for notification when they are eligible for research studies. Fifty-five percent of individuals agreed to join the registry and $49 \%$ wished to be added to the prospective subject list. This study demonstrated that a webbased system can potentially be used to recruit registry and study participants, reduce selection bias, protect patient privacy and link patient responses to electronic medical records.

Web-based registries can potentially be used to share resources internationally ${ }^{170}$ and provide fast and easy reporting of electronic patient data. ${ }^{100}$ Mitri et al developed a web-based registry of patients with congential heart defects at a hospital in Saudi Arabia. ${ }^{170}$ This internet method allowed for any web browser to perform registry functions such as: data-entry, data viewing, charting and exporting data.

A multi-centre web-based registry was developed by Prince et al to create a more effective method of data collection than paper based case record forms. ${ }^{100}$ This method was tested by 
entering data from 161 juvenile idiopathic arthritis patients. Treating physicians from nine centres found electronic data collection to be user-friendly with a reliable layout, sufficient amount of data collected and an acceptable amount of time needed to enter data.

Internet-based data collection may not be feasible for all age groups. Rolfson et al performed a study that examined the reliability of internet patient reported questionnaires and compared the response rates to mailed pen-and-paper questionnaires in 2,290 randomized participants from the Swedish Hip Arthroplasty register. ${ }^{171}$ Internet questionnaires demonstrated adequate reliability in 100 participants and can provide immediate online access, a decrease in manual errors, elimination of missing values and a reduction in human resources required to manually register data. Sixty-seven percent of responders felt secure answering questions online. However, response rates of internet questionnaires were significantly lower (49\%) when compared to (92\%) to pen-and-paper questionnaires $(\mathrm{p}<0.01)$. The study also found that internet response rates declined with increasing age $(\mathrm{p}<0.001)$. In this population internet questionnaires are feasible, but should be supplemented with a pen-and-paper based option.

Participant access to the internet and willingness to complete questionnaires need to be considered when planning data collection methods. Bhinder et al performed a study to determine the feasibility of online collection of health-related quality of life data in Canadian tertiary care patients. ${ }^{18}$ Fifty-seven percent of 644 patients surveyed were willing to complete questionnaires over the internet through an emailed link. Of these patients, 78\% completed at least one questionnaire. Lack of time was the most common reason patients failed to complete the questionnaire. This study found that young, single urban dwellers that were working, or in school were more likely to have internet access and willing to participate. These results suggest that online data collection is feasible, but alternative methods of data collection should be included.

Overall the literature cited several effective, economical methods that may improve registry data. Internet based recruitment methods are proving to be very cost effective and efficient at recruiting large number of patients quickly. ${ }^{62,168,169,172}$ Web-based databases are associated with a reduction in the time and resources needed for data management. ${ }^{27,52,100,168,173,174}$

\section{Other Considerations}

\section{Data Collection Strategies}

The different types of registries and methods of data collection are discussed in the Data Collection and Registry Configuration section of this document.

\section{Managing Expectations}

When developing registries and particularly online registries, a key element of success is to identify all potential stakeholders associated with the registry and ensure that their expectations are managed. Stakeholders might include physicians or other clinical staff; researchers and research support staff; patients and their families; pharmaceutical industry or government data end users; legal and ethics committees or offices; patient organizations or charities and the internal registry team which might include any or all of the above. Table 10 shows the possible expectations of each stakeholder group based on a review of literature in the area and this project's patient focus groups.

With these expectations in mind, key guiding themes to registry modalities and formatting should include:

1) Participation in the registry should not be onerous on any party.

a. Minimize time for data collection for both the patient and the provider

b. Minimize additional visits for patients and providers

c. Minimize total clinic burden through efficient datasets and software

2) Registry policies and procedures should be documented in clear and plain language.

a. Make these available to all stakeholders to ensure transparency.

3) Online registries should be designed with easy access and compatibility as key priorities.

a. Enables rapid sharing of data across sources and research teams

b. Enhances participant experience in contributing data.

4) Registries can be used to form and enhance investigator networks and patient experience.

a. Powerful communication vehicle with patients for educational and research recruitment purposes

b. Powerful mechanism for administering and monitoring clinical standards.

\section{Participant Enrollment in Online Registries}

A key consideration in operating an online registry is a mechanism for verifying that enrolling participants are indeed from the registry jurisdiction and desired target population. The Internet's configuration leaves substantial opportunities for accidental foreign participant involvement and/or involvement of participants outside of the target population. These situations could occur through accidental channels such as mis-reporting of target population characteristics, or deliberate activities such as internet protocol (IP) address re-routing or participant profile fabrication. One mechanism to prevent these occurrences is linking of registry enrollment with known clinic populations for participant verification. This could be done during registration via manual (e.g. physician messaging) or electronic methods (e.g. physician record search) or it can be done post-registration via auditing through linkage with administrative data for the appropriate jurisdiction. In a randomly selected sample, the NARCOMS (North American Research Committee on Multiple Sclerosis) Registry demonstrated a 98\% agreement between patient self-reported diagnosis and physician reported diagnosis, ${ }^{187}$ and demonstrates that robust methodology can contribute to successful recruitment of target population participants regardless of the registry type selected in the formation of the online registry.

\section{Privacy and Confidentiality in Online Registries}

In addition to the above challenges with relation to enrollment of participants, online registries also face challenges with respect to ensuring appropriate privacy and confidentiality for participants. Many of the data safeguards outlined in the Data 
Table 10: Managing Stakeholder Expectations

\begin{tabular}{|c|c|c|c|c|c|c|}
\hline \multicolumn{7}{|c|}{ AREAS OF EXPECTATION } \\
\hline STAKEHOLDER & TIME & $\begin{array}{l}\text { DATA COLLECTION } \\
\text { MODALITY }\end{array}$ & $\begin{array}{c}\text { DATA } \\
\text { SECURITY }\end{array}$ & DATA VISIBILITY & USER KNOWLEDGE & DELIVERABLES \\
\hline Physicians & \multirow[t]{2}{*}{$\begin{array}{l}\text { Burden is } \\
\text { minimal. } \\
(100)\end{array}$} & $\begin{array}{l}\text { Data entry is efficient and low cost. } \\
(100,175)\end{array}$ & \multirow{6}{*}{$\begin{array}{l}\text { Data security } \\
\text { should be } \\
\text { monitored by } \\
\text { a committee } \\
\text { not an } \\
\text { individual. }{ }^{(48)}\end{array}$} & $\begin{array}{l}\text { Data can be freely exchanged } \\
\text { and is comparable to other } \\
\text { sources }{ }^{(50,175)} \text { Online registries } \\
\text { may help to facilitate free } \\
\text { exchange. }{ }^{(100)}\end{array}$ & $\begin{array}{l}\text { Physician input has been } \\
\text { present during registry } \\
\text { design. }^{(176)} \text {. }\end{array}$ & $\begin{array}{l}\text { Results are relevant to clinical } \\
\text { practice or research interest. }{ }^{(176,177)} \\
\text { Educational outreach is a useful } \\
\text { activity paired with registries. }{ }^{(178)}\end{array}$ \\
\hline Clinical Staff & & $\begin{array}{l}\text { Data entry is efficient and pay is } \\
\text { reasonable. }{ }^{(100)}\end{array}$ & & & $\begin{array}{l}\text { Clear procedures for registry } \\
\text { execution are outlined. }{ }^{(49)}\end{array}$ & $\begin{array}{l}\text { Can be used as a tool to standardize } \\
\text { clinical practice. }{ }^{(177)}\end{array}$ \\
\hline Researchers & \multirow{2}{*}{$\begin{array}{l}\text { Using } \\
\text { registries for } \\
\text { recruitment } \\
\text { can save } \\
\text { time. }{ }^{(179)}\end{array}$} & & & $\begin{array}{l}\text { Rapid access to registry data } \\
\text { may be helpful. }{ }^{(179)}\end{array}$ & & \\
\hline Research Staff & & & & $\begin{array}{l}\text { Rapid access to registry data } \\
\text { may improve recruitment. }{ }^{(179)}\end{array}$ & & \\
\hline Patients & \multirow[t]{2}{*}{$\begin{array}{l}\text { No extra } \\
\text { visits will be } \\
\text { required for } \\
\text { data } \\
\text { collection to } \\
\text { minimize } \\
\text { transportation } \\
\text { hassles and } \\
\text { cost. } \\
(180-182)\end{array}$} & $\begin{array}{l}\text { Graduated levels of consent may } \\
\text { increase participation. }{ }^{(48)} \\
\text { Willingness to share medical } \\
\text { information is higher than personal } \\
\text { information. }{ }^{(183)}\end{array}$ & & $\begin{array}{l}\text { Data will be kept confidential } \\
\text { and not shared with } \\
\text { employers, insurance } \\
\text { providers etc. } \\
\text { Identifiers are acceptable data } \\
\text { points if the information will } \\
\text { be used for follow up contact } \\
\text { about research } \\
\text { opportunities. }{ }^{(184)}\end{array}$ & $\begin{array}{l}\text { Data collection purpose and } \\
\text { methods for release will be } \\
\text { clearly communicated. } \\
\text { Desire for prompt information } \\
\text { after diagnosis. }{ }^{(185)} \text { Perception } \\
\text { for equal knowledge and } \\
\text { information sharing between } \\
\text { patients and healthcare } \\
\text { practitioners. }{ }^{(185)}\end{array}$ & $\begin{array}{l}\text { Data will be used by responsible } \\
\text { people for legitimate purposes. }{ }^{(48)} \\
\text { Data will contribute to increased } \\
\text { knowledge of the disease, possible } \\
\text { elucidation of treatment and } \\
\text { improved patient quality of life in } \\
\text { the long-term. }{ }^{(186)} \\
\text { Regular educational outreach } \\
\text { specific to disease type and } \\
\text { featuring the latest information on } \\
\text { research and knowledge. }{ }^{(48,185,186)}\end{array}$ \\
\hline Families & & & & & & $\begin{array}{l}\text { Access to family support and } \\
\text { services (counseling, equipment, } \\
\text { peer support). }{ }^{(33)}\end{array}$ \\
\hline Ethics committee & & & & $\begin{array}{l}\text { Research or parties accessing } \\
\text { data will have the access/data } \\
\text { release reviewed by ethics. }{ }^{(12)}\end{array}$ & & $\begin{array}{l}\text { Regular reporting on registry } \\
\text { activities is required. }{ }^{(12)}\end{array}$ \\
\hline \multicolumn{7}{|l|}{$\begin{array}{l}\text { Patient } \\
\text { organizations }\end{array}$} \\
\hline Registry Team & & $\begin{array}{l}\text { To maximize registry success central } \\
\text { data collection and curation should be } \\
\text { considered. }{ }^{(50,51)}\end{array}$ & & & $\begin{array}{l}\text { Clear procedures for registry } \\
\text { execution are outlined. } \text { ( }^{(9)}\end{array}$ & $\begin{array}{l}\text { A research network that can provide } \\
\text { technical assistance and guidance } \\
\text { helps to ensure registry success. }\end{array}$ \\
\hline
\end{tabular}

Storage and Curation chapter apply to the construction of online registries just as they apply to other types of registries. Participant log-in credentials must be appropriately derived and should be stored in an encrypted manner. Additionally strategies to verify participant identity may be worthwhile such as personal verification questions or tokens utilized for other secure online functions such as online banking. When planning an online registry, ensure appropriate IT security and network consultants are involved in the registry design. Many institutions conducting research have these individuals' available and strict policies in place.

\section{Follow Up}

With all registries, the issue of attrition must not be overlooked. This may be a greater challenge for online registries which may have a higher degree of automation and depend less on the provider-participant relationship (e.g. patient driven registries). In Internet-delivered healthcare interventions attrition is a bigger concern than in interventions that are provided face to face. ${ }^{188}$ Possible sources of attrition might include declining interest in the registry; death; transfer out of the target clinic population and other attrition from follow-up. Attrition is a critical issue because it may introduce a selection bias into the registry data. There is a need for greater research in the areas of predictors of attrition and methods to address attrition specifically within the context of registries. One study did find a reduction in attrition using a blended follow-up approach where participants received both automated email reminders and telephone or in-person follow-up. ${ }^{188}$ Substantial literature discussing retention and attrition in longitudinal cohort studies may be helpful. For example, below are some general strategies to maximize retention based on the work of Hunt and White ${ }^{189}$ and Given et al. ${ }^{190}$

1) Assess participant willingness to participate over the long term during initial consent and baseline visits.

2) Cultivate participant bonding and commitment to the study through the use of logos and themes used on all communication with study participants.

3) Strive to contact participants at least once in a 6-24 month interval and track all follow-up activities.

4) Study staff should be well trained, communicate enthusiastically and openly, be flexible and respond promptly to questions or concerns.

5) Providing small branded tokens of appreciation; providing regular feedback about study progress and cash or other incentives for survey completion may help to improve participant retention.

\section{Internet Access}

According to the Canadian Internet Use Survey (CIUS) administered by Statistics Canada in $2010,79 \%$ of households had access to the internet and over half used multiple devices (e.g. desktop, laptop, mobile phone, game console) to access the Internet. ${ }^{190}$ Ninety-four percent of internet users over the age of 16 utilized email and $75 \%$ of these users reported accessing the 
internet at least once a day. ${ }^{191}$ Additionally, regardless of age over $60 \%$ of users accessed the internet to search for medical or health information. ${ }^{191}$ On average only $19 \%$ of users contributed content to the internet including activities such as message boards, blogging or posting images and this was in stark contrast to the average use of social networking sites at $58 \% .{ }^{191}$

The level of access was higher among urban metropolitan households compared with rural households $(81 \%$ in urban metropolitan vs. $71 \%$ in areas outside of metropolitan or agglomerate areas). ${ }^{190}$ Rates of access varied nationally and were highest in British Columbia, Alberta and Ontario. Rates of access were also highest in the upper income quartile $(\$ 87,000$ per household or more). Also, internet access also varied by household size with higher access rates in households with more than three members. ${ }^{190}$ About $75 \%$ of Canadian households have access to high speed home internet access. ${ }^{190}$ Over half of households that did not have internet access indicated that they had no need for internet access while other reasons for lack of access including lack of devices to access the internet; the cost of the service or equipment; and a lack of confidence about internet skills. ${ }^{190}$

Based on these data, limitations in internet access alone should not significantly contribute to online registry enrollment bias in Canada. However, lowered participation in activities requiring the contribution of content on the internet such as social networking and other activities should be considered a concern with respect to registry enrollment, online data collection and attrition potential. Further examination of motivations behind these statistics is likely warranted. A best practice strategy to addressing these knowledge gaps and the potential biases they may introduce would be to have a toll-free number available to all people interested in joining any online registry and a postal mailing option for any email correspondence. ${ }^{192}$ This would help to ensure that access was not a factor limiting enrollment and will not substantially increase time consumed by registry activities. ${ }^{192}$

\section{Knowledge Translation}

Knowledge translation, the ethically sound application of knowledge to improve the health of populations ${ }^{193}$ is an important obligation for registries. The immediacy and accessibility of online registries inherently lends themselves to knowledge translation activities. Some evidence suggests that patient engagement levels relate to attrition rates and that higher engagement will reduce attrition ${ }^{188}$ Some studies have expressed that registry participants desired regular communication of results (e.g. annual reports, newsletters) in lay language ${ }^{185}$ however it should be noted that while it was preferred that these were interactive, sophisticated technologies such as videos were not preferred. ${ }^{185}$ This indicates that a knowledge translation strategy such as an e-newsletter might be a very effective strategy with minimal cost. Additionally, registries that involve a network of practitioners may serve as good vehicles for enabling practice improvement. ${ }^{177}$ Our guideline for the development of knowledge translation plans for neurological registries includes the following steps based on the work of Melanie Barwick and Donna Locket ${ }^{193}$ :
1) Identify your target audience(s) - remember that this might include patients and families, disease organizations or charities, researchers, scientists, clinical providers, and institutional decision-makers depending on the purpose of your registry.

2) Engage members of your target audience(s) at appropriate times - plan engagement with members of your audience into your registry operations and determine at what intervals this engagement will occur at.

3) Determine main messages for each target audience - what is the minimum and critical information that must be communicated to each target audience. Think of the simplest way to express these elements.

4) Consider the packages for these main messages and what methods you will use to circulate them - there are no right or wrong strategies; consider planning an evaluation of each strategy to determine its effectiveness.

5) Determine the desired impact of your messages - identify the possible outcomes you hope for with the distribution of your messages. Plan how you will evaluate your success.

\section{RECOMMENDATIONS}

$\checkmark$ Consider registry objectives and data collection plans before establishing an online registry as the planned deployment.

$\checkmark$ Identify all potential stakeholders and ensure expectations are adequately managed.

$\checkmark$ Ensure a mechanism exists to verify that enrolled registrants are from the desired target population and registry jurisdiction.

$\checkmark$ Ensure participants are aware of registry expectations and willing to participate in the long-term.

$\checkmark$ Ensure activities are undertaken by the registry to cultivate participant bonding and commitment. Strive to contact participants at least once every $6-24$ months depending on registry needs. Track all follow-up activities.

$\checkmark$ Ensure study staff are well trained and highly knowledgeable. Communication needs to be open, flexible, and prompt.

$\checkmark$ Provide regular feedback to participants. Consider other ways in which appreciation may be expressed.

$\checkmark$ Ensure non-electronic methods of communication are open to participants (e.g. mailing address; fax number; toll-free telephone number).

$\checkmark$ Ensure a knowledge translation plan has been created and is actualized. 